\title{
Innovative Integrated Teaching for MBBS Undergraduates
}

\author{
Neena Nagdeo ${ }^{1}$ Tanuja Manohar $^{1}$, Anjali Kawthalkar ${ }^{1}$, Mohan Joshi ${ }^{1}$
}

\begin{abstract}
Medical colleges in India follow a curriculum with a large body of knowledge pertaining to basic sciences and clinical disciplines. Use of innovative techniques in teaching has certain advantages which include increasing teacher and learner enthusiasm and improving participation of the students. We combined the use of pre-/post-test in vertical integrated teaching to increase the effectiveness of the teaching process. An innovative vertical integrated teaching session was carried out for final MBBS students. A total of 35 students participated. A pre-test questionnaire was given to all the students to identify basic knowledge about the subject (HIV). Then the faculty conducted sessions on HIV, followed by a post-test questionnaire. This study revealed that students have improved their knowledge by the new teaching-learning method. The students were enthusiastic towards the new teaching-learning method. The faculty showed enthusiasm towards this new approach but were of the opinion that this method could be applicable only to selected topics. The teachers agreed that immediate feedback can be obtained from the students regarding acquisition of knowledge.
\end{abstract}

\section{Introduction}

Medical colleges in India follow a curriculum with a large body of knowledge pertaining to basic sciences leading to overburdening of students with content information. The subjects are taught in isolation with no attempt to integrate the basic sciences with the clinical discipline (Sood \& Adkoli, 2000). The Medical Council of India $(\mathrm{MCl})$ has recommended both horizontal and vertical integration to be introduced throughout the curriculum $(\mathrm{MCl}$, 1992). The pre-test helps in measuring true learning. By comparing the pre- and posttests, teachers can identify if students actually learned from the lessons. The pre-test can give students a preview of what will be expected of them. This helps students to focus on the key topics that will be covered (Kelly, n.d.).

Attempts have been made to combine the use of pre-tests in vertical integrated teaching to increase the effectiveness of the teaching process.

${ }^{1}$ NKP Salve Institute of Medical Sciences, Hingna Road, Nagpur, India.

Corresponding author:

Dr. Neena V. Nagdeo,

No. 75, Vivekanandnagar, Wardha Road,

Nagpur, India 440015

\section{Aims and Objectives}

This method was adopted for final year MBBS students to:

1. Introduce the concept of integrated teaching in undergraduate MBBS curriculum.

2. Improve the understanding of the subject.

\section{Material and Methods}

The Medical Education Technology Unit of NKP Salve Institute of Medical Sciences, Nagpur, India carried out innovative vertical integrated teaching for final year MBBS students in April 2010. Vertical integrated teaching was implemented by the active participation of the departments of Microbiology, Medicine, Obstetrics \& Gynaecology and Preventive and Social Medicine. A total of 35 students participated in this project. Students' knowledge regarding the topics was tested using a pre-test questionnaire. Then the students were taught the topics which included the pathogenesis of HIV, clinical manifestations, HIV in pregnancy, laboratory diagnosis and counselling of HIV patients. The teaching centred around questions raised in the pre-test.

A set of 20 questions was provided as the pretest, of which 15 were multiple choice and 5 were open ended questions. Following the pre-test, topics were presented by the respective teachers using PowerPoint presentations. After the session, a post-test questionnaire was given to assess the level of 
understanding. Questions were based on the specific learning objectives of the topics covered in the integrated teaching session.

\section{Results}

Results of the pre-test and post-test indicated an improvement in the acquisition of knowledge. Almost all the students were able to answer the questions correctly except for two questions (question numbers 13 and 15).

The entire faculty showed enthusiasm towards this new approach but were of the opinion that this method would be applicable only to certain selected topics. They agreed that immediate feedback from the students regarding acquisition of knowledge can be obtained.

\section{Discussion}

Modern teaching trends in medical education exhibit a change from conventional classroom teaching to newer methods which encourage interactive learning through active participation. It is well known that students learn more when involved actively in learning than when they are passive recipients of instructions (Nageswari et al., 2004). Joglekar et al. (1994) revealed the following advantages of integration:

1. Reduces fragmentation of medical courses

2. Prevents repetition and waste of time

3. Students learn to apply their knowledge to clinical practice

4. Promotes interdepartmental collaboration

5. Rationalization of teaching resources

However, the difficulties encountered were:

1. Lack of cooperation

2. Additional staff work in organising the course

3. The more the links in the chain of communication, the more likely that one will break

4. It is useless to provide an integrated course if the examination pattern is not integrated

HIV is a vast topic which is usually taught by many departments at different times without any correlation. This leads to unnecessary repetition, loss of valuable time and may create confusion in students' minds. The objective of medical education is to impart knowledge according to the health needs. As HIV is a vast topic it is not possible to cover all the issues pertaining to HIV. In this project, efforts were taken to teach certain issues which are important regarding patient care.
The issues were covered three times to make students aware about its importance, and promote deeper learning. Basic knowledge on HIV was determined by a pre-test, and following inputs by the teachers, students' acquisition of knowledge was determined by a post-test. Vertical integration provided a platform where students could correlate each subject properly in an organized and integrated manner.

$\mathrm{MCl}$ guidelines stipulate that interaction of the basic sciences departments with the clinical departments during the pre-clinical phase of medical education is mandatory. This study reveals that the students were enthusiastic, have improved cognitive domains by the new teaching-learning method and were benefitted by the clinico-pathological correlation.

\section{Conclusion}

Pre-test and post-test questionnaires can be used to evaluate the effectiveness of lectures. Integrated teaching offers many advantages, including system-wise teaching. Any assessment usually motivates students to do better. The post-test helped the faculty to identify the areas which need improvement. The present era requires shifting from independence to interdependence. Therefore instead of teaching the subjects independently by each department, all the faculty can come together for the benefit of the students.

\section{References}

Joglekar S., Bhuiyan, P.S. \& Kishore, S. (1994) Integrated Teaching-our experience, Journal of Postgraduate Medicine, 40, 4, pp 231-232.

Kelly, M. (n.d.) Pre-tests-Importance and use of Pre-tests, available at: Error! Hyperlink reference not valid. http://712educators. about.com/od/ assessments/a/pretests.htm.

Medical Council of India (1992) Recommendations of the workshop on Need based Curriculum for undergraduate medical education, $\mathrm{MCl}$ : New Delhi.

Nageswari, S.K., Malhotra, A.S., Kapoor, N. \& Kaur, G. (2004) Pedagogical effectiveness of innovative teaching methods initiated at the Department of Physiology, Government Medical College, Chandigarh, Advances in Physiology Education, 28, pp. 51-58.

Sood, R. \& Adkoli B.V. (2000) Medical Education In India- Problems and Prospects, Journal of Indian Academy of Clinical Medicine, 1, 3, pp 210-212. 